\title{
O BALLET CLÁSSICO E AS IMPLICAÇÕES ANATÔMICAS E BIOMECÂNICAS DE SUA PRÁTICA PARA OS PÉS E TORNOZELOS
}

Renata Duarte Simões

Aweliton Fernando Peres dos Anjos

O estudo identificou qual a prevalência de lesões no tornozelo e pé entre praticantes de ballet clássico na cidade de Vitória/ES, assim como seus aspectos causadores. Participaram da pesquisa 26 bailarinas com média de idade correspondente a 19,6 anos, que foram acometidas por lesão(ões) no tornozelo e/ou pé decorrentes da prática. Os dados foram coletados por meio de questionários semi-estruturados aplicados às dançantes. Concluiu que as lesões mais apresentadas foram as bolhas, calos, entorses, tendinites, hálux valgos (joanete), fraturas e luxações. Os principais causadores das lesões apontados foram: treinamento excessivo, os passos específicos do ballet clássico e o uso da sapatilha de ponta.

\section{Palavras-Chave}

Lesões no tornozelo e pé; Ballet clássico; Aspectos causadores.

\section{CLASSICAL BALLET AND THE IMPLICATIONS ANATOMICAL AND BIOMECHANICAL YOUR PRACTICE FOR FOOT AND ANKLE}

Renata Duarte Simões

Aweliton Fernando Peres dos Anjos

\begin{abstract}
The study identified to which the prevalence of injuries in the ankle and foot between practitioners of classical ballet in the city of Vitória/ES, as well as aspects that cause its. 26 dancers participated in the survey with the corresponding mean age 19,6 years, who had lesion(s) in the ankle and/or foot resulting from practice. The data were collected through semi-structured questionnaires applied to dancing. It concluded that the lesions were made more blisters, calluses, sprains, tendonitis, hallux valgus (bunion), fractures and dislocations. The main causes of the injuries identified have been: training excessive, the specific steps of classical ballet and the use of shoe-edge.
\end{abstract}

\section{Key-Words}

Iinjuries in the ankle and foot; Classical ballet; Aspects that cause. 


\section{INTRODUÇÃO}

A dança, uma das manifestações artísticas mais antigas da humanidade, tem o corpo como matéria-prima e o movimento como elemento estruturador. Como expressão estética que possibilita a sensibilização, ao organizar seus códigos nas suas diversas linguagens, ela produz e ocupa continuamente o espaço, transformando o estado do corpo em cada movimento que realiza. Para que isso ocorra, é necessária uma apurada integração dos sistemas corporais a fim de assegurarem a aquisição e a manutenção de domínios tão especializados e tão específicos (MARKONDES, 2001).

No âmbito da dança, os praticantes buscam constantemente a perfeição técnica e a melhora da performance artística. $\mathrm{O}$ corpo é empregado dentro do conceito de perfeccionismo. Além disso, há uma exigência corporal intensa distante da realidade anatômica e fisiológica de alguns dançarinos (MACEDO, 2007).

A dança tem no estilo ballet clássico seu "representante supremo" no que diz respeito à manutenção da tradição, da rigidez de movimentos e da exigência técnica. Muitos bailarinos realizam performances em vários estilos de dança, porém é o ballet clássico que requer um treinamento mais árduo e maior eficiência do sistema músculo esquelético por parte dos dançantes (STRETANSKI; WEBER, 2002).

$\mathrm{O}$ ballet clássico demanda várias habilidades e treinamentos físicos. Ele tem inerente à sua prática o desenvolvimento de exercícios que produzem eficiente potência muscular e coordenação. Para Malanga (1985), no campo motor o ballet clássico trabalha essencialmente a amplitude dos movimentos articulares, a coordenação, a flexibilidade, a precisão dos giros sobre ou fora do eixo corporal e o domínio do equilíbrio.

Embora se tenha conhecimento de que a dança contribui para a melhora do desempenho motor, a modalidade é comprometida quando, em busca da técnica perfeita, utiliza técnicas ortodoxas específicas, sem preocupação com a coordenação geral do indivíduo, desrespeitando a faixa etária ou provocando movimentos e atitudes estereotipadas (GREGO et al., 2006). 
O treinamento excessivo, incorreto, mal planejado ou inexistente pode levar a lesões crônicas, como a fratura por stress no tornozelo e tendinites, frequentes em bailarinas clássicas, causadas pelo alto número de repetições exigido para aperfeiçoamento da performance (MONTEIRO; GREGO, 2003).

O estudo realizado por Wiesler et al. (1996) aponta que em busca da perfeição e precisão de padrões de movimentos, $56 \%$ das bailarinas clássicas apresentam, em algum momento de suas vidas, lesões músculo-esqueléticas.

Vários são os fatores que contribuem para o surgimento de lesões em bailarinos(as) clássicos(as). Eles podem ser divididos em fatores extrínsecos, como calçados, piso e temperatura inadequados; e fatores intrínsecos, como encurtamento muscular, hipermobilidade, fraqueza muscular, dietas inadequadas, entre outros (LIANZA, 2001; DELISA; GANS, 2002; DELIBERATO, 2002).

A combinação de fatores extrínsecos e intrínsecos pode acarretar os mais diversos comprometimentos. Como principais lesões em bailarinos clássicos destacam-se o calo macio, calo duro, bolha, hálux valgus (joanete), hálux rígido, entorses no tornozelo, fratura de estresse no tornozelo, sesamoidite, bursite no tornozelo e joelhos, neuroma de Morton, tendinites (região do pé, tornozelo, joelhos e quadril), laceração do menisco, luxação e subluxação do tornozelo e da patela, contusões, lesão ligamentar, abrasão, quadril estalante, artrite degenerativa no quadril, lombalgia, espondilolistese degenerativa, espondilólise e radiculopatia lombar (dor no ciático) (MONTEIRO; GREGO, 2003).

As lesões de tornozelo e/ou pé, freqüentes em bailarinos que se dedicam várias horas por dia ao ballet, podem incidir em vários seguimentos da estrutura como nas articulações talocrural e tarsometatarsica, nos músculos da região e nos tendões (SALOMÃO et al., 1993).

O ballet sobrecarrega especialmente os membros inferiores, aumentando a predisposição para lesões. O treinamento exaustivo que envolve as articulações em posições excessivas, geralmente, é composto por exercícios de aquecimento, alongamento, flexibilidade, quedas, saltos, equilíbrio, amplitudes exageradas de movimento, forças dinâmica, estática e explosiva, giros, trabalho sobre sapatilha de ponta, resistência aeróbica, anaeróbica, entre outros, tudo para buscar o sincronismo perfeito e a técnica apurada, exigências que levam os dançantes ao limite do que é suportável pelos mecanismos fisiológicos (LIMA, 1995). 
Em função do número elevado de lesões sofridas por bailarinos e da reconhecida necessidade de direcionar atenções para os acometimentos acarretados pela prática do ballet clássico, estudos tem realizado esforços na tentativa de identificar as deficiências na aptidão física dessa população, elaborando algum tipo de treinamento que seja específico as suas necessidades físico-funcionais (KUNO et al., 1996).

Apesar desses esforços, segundo Antunes (2006), poucas pesquisas tem sido publicadas sobre a relação entre dança e lesão no bailarino, o que tem conduzido ao desconhecimento dos cuidados necessários a serem tomados durante a prática dessa modalidade.

A falta de informação por parte dos bailarinos sobre o seu próprio corpo faz com que o número de lesões seja ainda maior. Também colabora para essa ocorrência o fato de muitos professores de dança estarem totalmente despreparados para orientar seus alunos em questões anatômicas, cinesiológicas e fisiológicas, questões essas que estão diretamente ligadas à prática da dança no que se referem ao rendimento técnico e ao máximo de segurança.

No ballet clássico, que demanda um grau elevado de desenvolvimento de aptidões físicas, um erro comum é privilegiar a flexibilidade e negligenciar o trabalho de força e de outros componentes do condicionamento, o que pode levar desde perdas na performance até a ocorrência de lesões irreparáveis e falta de motivação para a dança.

A sapatilha de ponta, associada a movimentos específicos, é mais um motivador de destaque no desenvolvimento de lesões, uma vez que ela não é desenhada a fim de proteger os pés contra estresses físicos (PICON et al., 2002).

As diversas posições de ponta do ballet clássico, que diferem de acordo com a posição dos pés entre si, possuem em comum a base de sustentação extremamente diminuída, o que requer um grande esforço muscular e neurofisiológico. Somados a essa base diminuída tem-se os impactos nos saltos e giros que contribuem para graves lesões ligamentares, musculoesqueléticas e articulares, principalmente dos membros inferiores (BARCELLOS; IMBIRIBA, 2002). 
O início precoce da utilização das sapatilhas de ponta tem sido apontado como um dos fatores determinantes para o ocasionamento de lesões. Sabe-se que os exercícios realizados sobre a ponta dos pés constituem um trabalho muito estressante e que exige treinamento gradual da bailarina como um todo, além de coordenação e colocação de cada parte do corpo, com distribuição uniforme de peso sobre os pés (sem tendência de maior descarga de peso em algum dos dedos, prejudicando o alinhamento), com joelhos esticados e perfeito equilíbrio (KHAN et al., 1995).

Por conta dessa prática precoce e equivocada, encorajada já há muitos séculos, as bailarinas desenvolvem lesões características, como: tendinopatias, hálux rígido, sesamoidites. Por isso, segundo Toledo et al. (2004), o uso da sapatilha de ponta deve ser realizado pelas estudantes de ballet com 12 ou mais anos de idade, sendo esse o critério principal para a sua iniciação. O fator idade torna-se um indicador porque as epífises de crescimento, geralmente, não estão solidificadas antes dessa idade e o crescimento ósseo ainda ocorrerá por alguns anos, portanto, mesmo com 12 anos, a submissão ao trabalho nas pontas dos pés não deve ocorrer arbitrariamente.

Guimarães e Simas (2001) justificam que essa idade foi determinada porque é quando a extremidade inferior está suficientemente forte para manter o equilíbrio e o alinhamento correto sem a ajuda proporcionada pelo contato de todo o pé no chão. Logo, o sustentar sobre as pontas não é somente uma evolução técnica, mas também uma adaptação do corpo a uma nova forma de equilíbrio, com fortalecimento ósseo, tendíneo, ligamentar e muscular.

Deve-se ressaltar também que ter um piso flexível é muito importante para a prática do ballet com segurança. O impacto no solo, após um salto, se inapropriado o solo, pode acarretar diversas lesões. Para Guerra (2006), o que se encontra na maioria das escolas de dança está muito aquém do desejado, pela falta de infra-estrutura adequada para salas de aula, e até mesmo pelo despreparo de muitos profissionais que atuam no mercado da dança.

Nesse sentido, compreendendo que muitas das lesões são situacionais e acarretadas pela prática do ballet clássico, o presente estudo objetiva identificar qual a prevalência de lesões no tornozelo e pé entre praticantes dessa modalidade na cidade de Vitória, assim como seus causadores. 
O interesse pela temática emerge a partir de anseios e inquietações acerca da prática do ballet clássico, despertados nas disciplinas do Centro de Educação Física e Desportos da Universidade Federal do Espírito Santo - CEFD/UFES e a partir do contato com colegas graduandos em Educação Física e praticantes dessa atividade.

A pesquisa se justifica por repensar a prática do ballet, enquanto atividade secular na qual a estética e performance são buscadas a todo custo, ocasionando prejuízos físicos a seus praticantes. Para tanto, foi realizado um levantamento bibliográfico através do qual foi verificado que poucos estudos buscaram investigar os efeitos da prática do ballet nas articulações do tornozelo e pés dos bailarinos, principalmente na cidade de Vitória/ES. Logo, busca ainda preencher lacunas em estudos já realizados, estimulando em pesquisadores, estudiosos, professores e praticantes, um novo olhar acerca da prática do ballet e buscando proporcionar ao bailarino maior conhecimento de sua prática e possíveis formas de prevenções e tratamentos de lesões de tornozelo e/ou pé. Finalmente, intenta colaborar para o fomento de novas pesquisas a partir desta.

A pesquisa foi realizada na cidade de Vitória, situada no estado do Espírito Santo, de junho a novembro de 2008, em duas grandes escolas de ballet clássico.

A população selecionada para a concretização do estudo foi constituída de bailarinas que praticam o ballet clássico regularmente e realizam seu treinamento em Vitória.

O critério de inclusão para a pesquisa foi a bailarina ter praticado ballet clássico durante o tempo mínimo de dois anos, pois é um período hábil para que ela adquira conhecimentos específicos sobre o ballet e inicie a realização de movimentos de maior exigência técnica e de maior grau de dificuldade; ter no mínimo 12 anos e no máximo 30 anos de idade; e ter sofrido lesões no tornozelo e/ou pé decorrentes dessa prática.

Os dados foram coletados por meio de questionário semi-estruturado e individual, por possibilitar a investigação em um grande número de sujeitos e ao mesmo tempo permitir a familiaridade com o tema proposto. 
Para análise dos dados foram utilizadas as respostas obtidas nos questionários aplicados aos dançarinos, sendo organizadas de forma agrupada com análise quantitativa e qualitativa dos dados.

Assim, a pesquisa foi desenvolvida com o intuito de responder aos seguintes questionamentos: quais os principais fatores que levam o bailarino a lesionar-se na região do tornozelo e/ou pé? Quais os principais causadores dessas lesões?

\section{ANÁLISE DOS DADOS E RESULTADOS}

A média de idade das bailarinas entrevistadas foi de 19,6 anos, variando de 16 a 27 anos de idade. A média de tempo de prática foi de 9,9 anos, variando de 4 a 17 anos de prática. Comparando a idade com o tempo de prática de cada bailarina, pode-se perceber que a maioria delas não iniciou precocemente a prática do ballet clássico. Apenas 4 bailarinas ingressaram no ballet antes dos 7 anos, idade a partir da qual a literatura da área considera ideal para o ingresso nessa modalidade.

Bertoni (1992) destaca que a faixa etária ideal para o início do aprendizado do ballet clássico seria entre 8-9 anos. Contudo, na maioria das vezes, a criança começa a dançar entre 4-5 anos de idade, quando ainda não possui uma estrutura osteomuscular adequada para essa atividade. Segundo o autor, o início da prática prematura pode desenvolver diversas alterações corporais na criança, pois existem posturas, movimentos, passos na dança que se contrapõem a anatomia e biomecânica humana, como, por exemplo, os pés que sempre estão em rotação externa ou en dehors, a exigência de que os membros inferiores estejam sempre em extensão, entre outros.

Apesar das informações supracitadas terem sido utilizadas como orientação para realização deste estudo, pode-se constatar, através dos dados coletados, que no grupo entrevistado o início precoce não foi um fator determinante para o surgimento de lesões no tornozelo e/ou pé, pois de 26 bailarinas entrevistas com lesão nesses locais apenas 4 iniciaram a prática antes da idade recomendada.

Em relação ao tempo dedicado ao treinamento, as bailarinas afirmam treinar em média 25 horas semanais, sendo cerca de 3 horas desse total destinadas às aulas teóricas. Esse dado indica que as bailarinas chegam a treinar 5 horas por dia, sendo submetidas a repetições sucessivas de posições antianatômicas e tendo o sistema músculo-esquelético constantemente submetido a sobrecargas elevadas.

Conexões: revista da Faculdade de Educação Física da UNICAMP, Campinas, v. 8, n. 2, p. 117-132, maio/ago. 2010. ISSN: $1983-9030$. 
Para Wiesler et al. (1996), esses treinamentos repetitivos e exaustivos podem ser a causa de desequilíbrios musculares que alteram a biomecânica do sistema músculo-esquelético-ligamentar, comprometendo, assim, sua função.

O excesso de carga nas fibras musculares e nas estruturas ósseas na prática dessa atividade pode ocorrer, entre outros fatores, porque há uma exigência muito grande das articulações do quadril para realizar movimentos de rotação externa e abdução com grandes amplitudes, as quais geralmente não são alcançadas, e isso prejudica as articulações das extremidades inferiores que passam a realizar um esforço maior como forma de compensar tal amplitude exagerada (MONTEIRO; GREGO, 2003).

Foram encontradas nas bailarinas desde lesões simples como bolhas até lesões mais graves como fratura e luxação. Algumas delas ainda mencionaram já ter sofrido mais de um tipo de lesão ao longo de suas experiências com o ballet. A tabela abaixo mostra a relação e proporção das lesões encontradas.

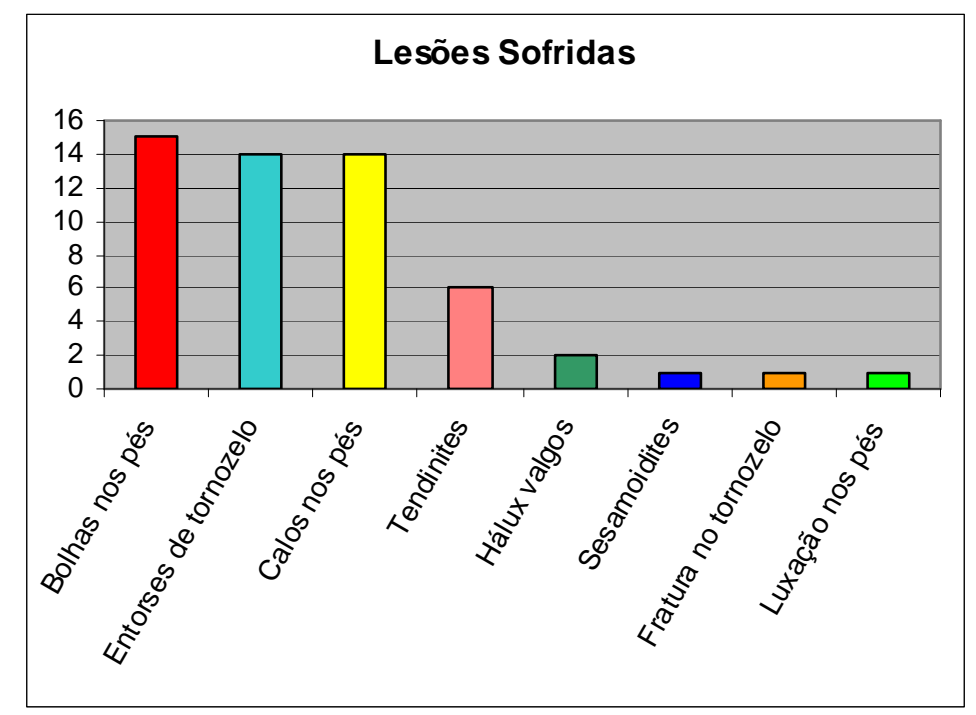

Gráfico I - Lesões que acometem tornozelos e pés das bailarinas entrevistadas.

Vitória - ES, 2008.

A respeito das bolhas, 11 das 15 bailarinas que apresentaram a lesão associam o uso da sapatilha de ponta ao treinamento excessivo para explicar o seu surgimento. As dançantes argumentam que a repetição exaustiva dos exercícios realizados com a sapatilha de ponta promove o desgaste dos pés e lesões que, se não cuidadas, se tornam feridas expostas. 
Das 15 bailarinas já lesionadas com bolhas, todas afirmam ter adquirido-as várias vezes durante os treinamentos. Algumas apontaram o agravamento dessas lesões, como sangramentos e inflamações. Uma das bailarinas relatou ter tido uma bolha que se tornou larga e profunda, necessitando de um pequeno enxerto.

As bolhas apresentaram-se como a lesão mais comum entre as bailarinas e, pelo revelado, não se tornam impedimento para a prática da atividade. As bailarinas relataram que, quando as adquirem, o que é muito comum, não se afastam das aulas e ensaios rotineiros, simplesmente enfaixam os dedos e utilizam "receitinhas" caseiras para acelerar a cicatrização.

Através das respostas das bailarinas que sofreram e sofrem com bolhas, pode-se observar como ponto causador em comum para essa lesão o uso da sapatilha de ponta, cujos materiais empregados para a composição - cola, cetim, papéis especiais, gesso e palmilhas flexíveis - são incapazes de oferecer proteção aos pés contra a atuação de forças externas (SAMARCO; MILLER, 1982).

As sapatilhas de ponta, introduzidas no ballet clássico no período histórico denominado Romantismo (1750-1850), depois de séculos passados, pouco evoluíram no sentido de oferecer conforto e diminuir as agressões aos pés das bailarinas.

Outra problemática acarretada pelo uso contínuo da sapatilha de ponta e apresentada por Picon et al. (2002), diz respeito às lesões típicas que acometem os tornozelos de bailarinas. Segundo o estudo, a sapatilha de ponta é desenhada para dar leveza e graciosidade ao movimento, proporcionando um apoio de todo o peso corporal sobre a ponta dos dedos. Contudo, a posição assumida pelo pé em seu uso acaba negligenciando a proteção contra estresses físicos, potencializando o surgimento de lesões.

Para dançar sobre a ponta dos pés e usar as sapatilhas de ponta, mantendo-se uma técnica adequada, as bailarinas necessitam de um elevado grau de flexão plantar (em torno de 90 graus) do complexo tornozelo-pé. Essa grande amplitude de movimento é resultado das constantes flexões plantares que ocasionam alguns graus de modelação óssea. Segundo Hamilton et al. (1992) essa modelação do tornozelo acontece para compensar a hiperextensão do joelho, normalmente presente nas bailarinas clássicas. 
Sobre a entorse de tornozelo, 14 bailarinas apresentaram essa lesão, sendo que 12 delas destacam algum tipo de passo do ballet como o causador, principalmente os passos que realizam saltos. Duas bailarinas, entre as que sofreram entorses, apontam como causa de suas lesões a realização de treinamentos em excesso.

Assim como Grego et al. (2006) que em sua pesquisa no American Dance Festival encontrou a entorse de tornozelo como uma lesão muito freqüente nas bailarinas do festival, nesta pesquisa foi encontrado um número elevado de casos de entorse (14 bailarinas de 26), o que é um fator preocupante, pois se trata de uma lesão grave. A entorse causa a frouxidão ligamentar na região do tornozelo proporcionando facilmente novas entorses.

Pesquisas realizadas pela Gaynor Minden Statment (2001) apontam que um melhor alinhamento do corpo sobre a sapatilha de ponta, em relação à linha de gravidade, de apenas dois graus, é o suficiente para aliviar uma carga de até $18 \mathrm{~kg}$ sobre os tornozelos. O estudo aponta que uma medida simples e de caráter preventivo poderia reduzir consideravelmente o número de lesões graves que acometem as dançantes.

Sobre os calos, 14 bailarinas afirmaram ter sofrido tal lesão, sendo apontadas diferentes causas. Dentre esse grupo, 4 destacam o treinamento excessivo como o fator que ocasionou os calos; 5 apontam os exercícios realizados na ponta como causadores de suas lesões e outras 4 afirmam que seus calos surgiram devido aos passos do ballet aliados ao excesso de treino. Apenas uma bailarina argumenta que sua lesão surgiu devido aos passos do ballet, ao treinamento e aos exercícios na ponta, ou seja, somente uma delas aponta que o conjunto dos três fatores, relacionados, é o grande causador de seu stresse físico. Em relação às seqüelas por calos, 6 bailarinas afirmam que possuem o pé muito deformado e constantemente sentem dor no local. As dores nos pés são muito relatadas por bailarinas clássicas, que, frequentemente, se encontram com os pés feridos. Uma das bailarinas mencionou que não consegue usar sapatos fechados por muito tempo em função dos calos que se formaram sobre os dedos, acarretando-lhe fortes dores.

A respeito das tendinites, 6 dançantes apresentaram a lesão. Todas elas afirmaram que suas tendinites foram causadas pelo excesso de treinamento. Autores como Grego et al. (2006) e Wiesler et al. (1996) apontam que o excesso de treinamento com repetições excessivas e posições antianatômicas dos passos do ballet clássico fazem com que o surgimento dessas lesões seja inevitável. Uma das bailarinas destaca

Conexões: revista da Faculdade de Educação Física da UNICAMP, Campinas, v. 8, n. 2, p. 117-132, maio/ago. 2010. 
que sua tendinite foi tão grave que necessitou de sessões intensas e contínuas de fisioterapia, assim como o afastamento total dos treinos e aulas de ballet.

Sobre o Hálux Valgo ou Joanete, apenas 2 bailarinas apresentaram a lesão e ambas relacionam o seu surgimento a passos específicos do ballet. Elas também apontam que a dor no local da lesão é habitual, além da deformidade no pé, prejudicando a estética. Segundo Einarsdóttir et al. (1995) essa é uma deformidade típica do praticante de ballet devido ao formato antianatômico da sapatilha de ponta que provoca o estrangulamento dos dedos.

De acordo com Bertoni (1992), os pés não devem ser comprimidos na sapatilha, pelo contrário, ela deve preservar o posicionamento dos dedos entre si mantendo sua estruturação anatômica, possibilitando a elevação na ponta de modo a formar uma continuidade dos pés, pernas, tronco e cabeça, o que permitirá a estabilidade do arco plantar e, conseqüentemente, o equilíbrio.

A lesão por sesamoidite ocorreu apenas em uma das bailarinas durante a execução de um passo e ela relata que foi apenas uma pequena inflamação que rapidamente foi curada.

As lesões por fratura e luxação também foram sofridas apenas por uma das bailarinas devido a passos específicos e excesso de treinamento. A bailarina alega que a fratura lhe causa dor e a luxação lhe deixou com um dedo do pé torto.

A respeito de como surgiram as lesões, apenas três causas foram apontadas pelas bailarinas: exercícios realizados na ponta, treinamento excessivo e a realização de passos específicos. Abaixo, encontra-se um gráfico que mostra numericamente a incidência de cada causa mencionada. 


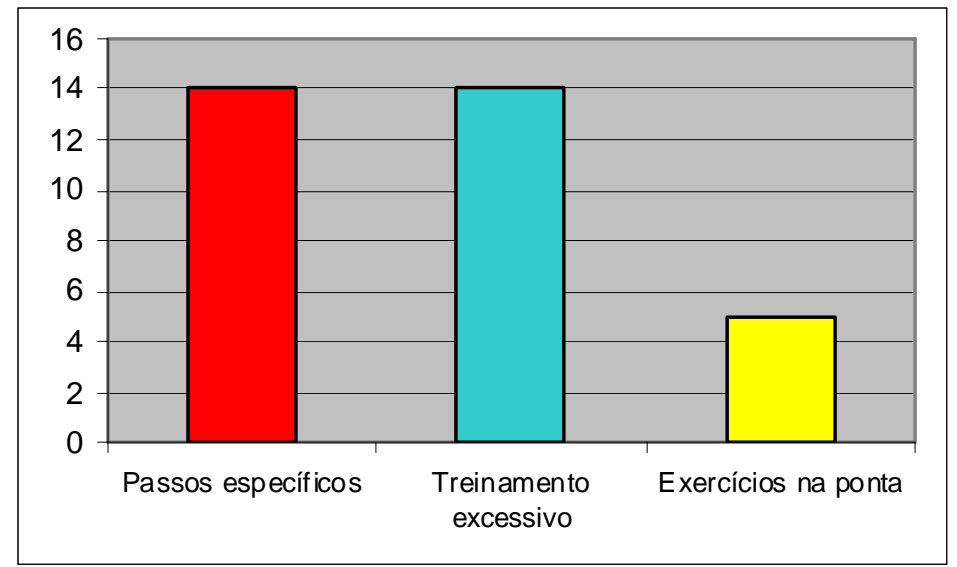

Gráfico II - Incidência das causas das lesões de tornozelo e pé nas bailarinas entrevistadas. Vitória - ES, 2008.

Os passos específicos e o treinamento foram apontados 14 vezes pelas bailarinas, sendo que 6 delas destacam a relação entre ambos os fatores como a maior causadora de lesões. Nota-se que o treinamento excessivo e os passos específicos do ballet clássico aparecem como as principais causas de lesões mais graves como tendinites e entorses.

Quanto a sapatilha de ponta, é interessante observar que as respostas dos questionários apontam para a sua estrutura como potencializadora de lesões, mas não reconhecem os exercícios propostos para serem realizados com ela problemáticos em suas execuções.

Explica-se, assim, porque, apesar das bailarinas compreenderem ser a sapatilha de ponta um fator decisivo na ocorrência de lesões, os exercícios na ponta foram pouco apontados. Isso pode ter ocorrido em função das bolhas e calos superarem quantitativamente as demais lesões apresentadas e estarem diretamente ligados ao material de composição da sapatilha. Das 26 bailarinas que responderam ao questionário, 25 ressaltaram que a sapatilha ocasiona lesões.

A forma da sapatilha de ponta atualmente colabora expressivamente para o surgimento de lesões, por se tratar de um calçado secular, em quase nada aprimorado para conferir conforto aos pés e articulações. Através dos conhecimentos atuais em biomecânica é possível desenvolver sapatilhas de ponta que minimizem cada vez mais o risco de lesões, assim como ocorre em outras modalidades esportivas. Contudo, esse fator deve estar associado a um repensar a prática do ballet clássico que pouquíssimo se aprimorou ao longo dos séculos. 
A fim de se evitar lesões, a adaptação do corpo nos treinamentos deve ser lenta e gradual para a obtenção da posição em ponta, evitando desalinhamento e frouxidão das articulações, exigindo força muscular e equilíbrio postural e tendo atenção especial para as articulações tíbio-társicas, tarso-metatarsianas, metatarso-falangianas e interfalangianas.

\section{CONCLUSÃO}

As lesões encontradas no tornozelo e pé das bailarinas participantes do estudo foram: bolhas, calos, entorses, tendinites, hálux valgos, sesamoidites, fratura e luxação, sendo caracterizadas pelo uso da sapatilha de ponta, pelos passos antianatômicos do ballet clássico, pelos exercícios realizados na ponta e pela alta demanda de treinamento que essa dança exige.

Assim, as medidas preventivas devem incluir o preparo adequado dos aspectos físicos e mentais; o uso de roupas e calçados adequados; o conhecimento acerca dos fatores climáticos e dos principais tipos de lesão em casos de frio ou calor extremos; alimentação equilibrada, com a ingestão de grande quantidade de líquidos diariamente; repouso adequado nos períodos entre apresentações ou competições; análise das condições das superfícies onde a dança será praticada; proteção das áreas mais susceptíveis a lesões e prática de atividades físicas compensatórias (DELIBERATO, 2002).

Pensando em sua prática secular e em seus exercícios antianatômicos, a melhora da performance em níveis seguros é possível pelas contribuições dos estudos de treinamento aliados a estudos nutricionais e comportamentais que dão base para melhorias nas condições de trabalho de dançarinos, proporcionando adequação de volumes e cargas, prevenindo lesões, afastamento precoce e desgastes excessivos e dando salto qualitativo na performance.

Uma boa estruturação do treinamento de longo e curto prazo e a preparação física adequada dos bailarinos possibilitará um aumento significativo na prevenção de lesões.

\section{REFERÊNCIAS}

Conexões: revista da Faculdade de Educação Física da UNICAMP, Campinas, v. 8, n. 2, p. 117-132, maio/ago. 2010. ISSN: 1983-9030. 
ANTUNES, S. S. Flexibilidade e lesão no tornozelo do bailarino. Disponível em: (http://www.bailarinas.kit.net/Artigos/artigos_-_tornozelo.htm). Acesso em: 04 set. 2006.

BARCELLOS, C.; IMBIRIBA, L. A. Alterações posturais e do equilíbrio corporal na primeira posição em ponta do balé clássico. Rev Paul Educ Fis, São Paulo, v. 16, n. 1, p. 43-52, jan./jun. 2002.

BERTONI I. G. Dança como fator educacional. In: A dança e a evolução. São Paulo: Tanz do Brasil, 1992. p. 55-58.

DELIBERATO, P. C. P. Fisioterapia preventiva: fundamentos e aplicações. São Paulo: Manole, 2002.

DELISA, J.; GANS, B. M. Tratado de medicina de reabilitação: princípios e práticas. São Paulo: Manole, 2002. v. 2.

EINARSDÓTTIR, H.; TROELL, S.; WYKMAN, A. Halux valgus in ballet dancers: a myth? Foot Ankle Int, v.16, n. 2, p. 92-94, 1995.

GREGO, L. G. et al. Agravos músculo-esqueléticos em bailarinas clássicas, não clássicas e praticantes de educação física. Arq Cien Saúde, São Paulo,v.13, n. 3, jul./set., 2006.

GUERRA, H. $\quad$ S. Lesões $n a$ dança. Disponível em: (http://www.conexaodanca.art.br/imagens/textos/artigos/Les\%F5es\%20na\%20Dan\%E7a.htm) Acesso em: 25 ago. 2006.

GUIMARÃES, A. C. A.; SIMAS, J. P. N. Lesões no ballet clássico. Rev Educ Fis, v. 12, n. 2, p. 86-96, 2001.

HAMILTON, G. W. et al. A profile of the musculoskeletal characteristies of professional ballet dancers. Am J Sports Med, v. 20, n. 3, p. 267-273, 1992.

KHAN, K. et al. Overuse Injuries in classical ballet. Sports Med, v. 5, n. 19, p. 341-357, 1995.

KUNO, M. et al. Anthropometric variables and muscle properties of japanese female ballet dancers. Int $J$ Sports Med, v. 17, p. 110-105, 1996.

LIANZA, S. Medicina de reabilitação. 3. ed. Rio de Janeiro: Guanabara Koogan, 2001.

LIMA, L. Dança como atividade física. Rev Bras Med Esporte, v. 3, n. 1, p. 94-96, jul./set., 1995.

MACEDO, C. G. Caracterização do treinamento e do gasto energético de praticantes de dança contemporânea e do ballet clássico. 2007. Trabalho de Conclusão de Curso (Graduação em Educação Física) - Universidade Federal de Goiás, Goiás, 2007.

MALANGA, E. B. Comunicação e balê. São Paulo: EDIMA, 1985.

MARKONDES, E. O movimento na dança. Dança \& Cia, São Paulo, v. 4, n. 3, ago./set. 2001.

Conexões: revista da Faculdade de Educação Física da UNICAMP, Campinas, v. 8, n. 2, p. 117-132, maio/ago. 2010. ISSN: $1983-9030$. 
MONTEIRO, H.; GREGO, L. As lesões na dança: conceitos, sintomas, causa situacional e tratamento. Motriz, Rio Claro, v. 9, n. 2, p. 63-71, 2003.

PICON, A. P. et al. Biomecânica e ballet clássico: uma avaliação de grandezas dinâmicas do sauté em primeira posição e da posição en pointe em sapatilhas de pontas. Rev Paul Educ Fis, São Paulo, v. 16, n. 1, p. 53-60, jan. 2002.

SALOMÃO, O. et al. Lesões tendíneas no pé e no tornozelo do esportista. Rev Bras Ortop, São Paulo, v. 28, n. 10 , out. 1993.

SAMMARCO, G. J.; MILLER, E. H. Forefoot conditions in dancers: part I. Foot and Ankle, Baltimore, v. 3, p. 85-92, 1982.

STRETANSKI, M.F; WEBER, G.J. Medical and rehabilitation issues in classical ballet: Literature review. Am J Phys Med Rehab, n. 81, p. 383-391, 2002.

TOLEDO, S. D.; AKUTHOTA, V., DRAKE, D.F., NADLER, S.F., CHOU,L.H. Sports and Performing Arts Medicine. Issues relating to dancers. Arch Phys Med Rehab, n. 85, v. 1, p. 75-78, mar., 2004.

WIESLER, E. R. et al. Ankle flexibility and injury patterns in dancers. Am J Sports Med, v. 24, n. 6, p. 754-757, 1996.

\section{RENATA DUARTE SIMÕES}

Universidade de São Paulo/USP. Integrante do Núcleo Interdisciplinar de Estudos e Pesquisa em História da Educação na mesma Faculdade.

\section{AWELITON FERNANDO PERES DOS ANJOS}

Universidade Federal Do Espírito Santo/Ufes

\section{Referência do artigo}

\section{ABNT}

SIMÕES, R. D.; ANJOS, A. F. P. O ballet clássico e as implicações anatômicas e biomecânicas de sua prática para os pés e tornozelos. Conexões, v. 8, n. 2, p. 117-132, 2010

\section{APA}

Simões, R. D. \& Anjos, A. F. P. (2010) O ballet clássico e as implicações anatômicas e biomecânicas de sua prática para os pés e tornozelos. Conexões, 8(2), 117-132. 


\section{VANCOUVER}

Simões, R, Anjos, AFP. O ballet clássico e as implicações anatômicas e biomecânicas de sua prática para os pés e tornozelos. Conexões, 2010; 8 (2): 117-132.

Artigo recebido em: 22 mar./2010

Aceito para publicação em: 29 jun./2010 